\title{
Ras-Related Protein Rab-5C
}

National Cancer Institute

\section{Source}

National Cancer Institute. Ras-Related Protein Rab-5C. NCI Thesaurus. Code C104816.

Ras-related protein Rab-5C (216 aa, $\sim 23 \mathrm{kDa}$ ) is encoded by the human RAB5C gene.

This protein plays a role in GT Pase activity. 